\title{
How to open my eyes? \\ The performance-lecture as a method within artistic research
}

\author{
BELÉN CEREZO, Nottingham Trent University.
}

\begin{abstract}
This paper presents and examines my research/work How to open my eyes? as a case study attempting to highlight the tactic of the performance-lecture as an important critical method within artistic research. As a brief definition, the performance-lecture is a hybrid and heterodox form what contains performative and discursive components. Since the 1990s the performance-lecture is gaining prominence within contemporary artistic practices and the number of visual and performance artists that use this format is growing. However, David Ladnar noted that despite its ubiquity, the notion of the performance-lecture is still contested and the bibliography on it is short. Within this context, and focusing on artistic research, the aim of this paper is to analyse how the performance-lecture operates as a method that generates new knowledge, drawing on the interrogation of the research/work How to open my eyes? produced practice-led $\mathrm{PhD}$ enquiry, on some of the bibliography on the format of the performance-lecture and on my experience as a part of the audience of several performancelectures.
\end{abstract}

\section{KEYWORDS}

Performance-lecture, performativity, the essay, the voice, artistic research

\section{Introduction}

Within my practice-led PhD research entitled "What is it "to move" a photograph? Artistic tactics for destabilising and transforming images' I explored how artistic practices intervening in existing images, 'move' images — in the sense of destabilisation and transformation. At the outset of the investigation, the main aim was to examine these tactics that are never permanent and change depending on the circumstances, as Michel De Certeau described (1984). In parallel to analysing how images function, as this was crucial to conduct operations with them, this inquiry examined the artistic tactics of gleaning, working with archives, the performance-lecture, montage and a tactic I have called 'performing documents'. These artistic tactics offered new insights regarding the operations of decontextualisation and re-contextualisation, montage, the categories of the still and the moving image and the 'affective encounter' that stems from touching.

Importantly, one of the new emerging critical tactics within my research was the so-called performance-lecture. Indeed, this tactic was key in the production of several works. This paper will analyse the usage of the tactics of the performance-lecture, in combination to 'performing documents', in my research/work How to open my eyes? in order to answer central research questions such as: What are the features that would define a performance- 
lecture? How has this tactic contributed the development of my artistic enquiry? What is its potential for artistic research? How might the performance-lecture enable an innovative, experimental and speculative research practice?

\section{An approximation to the definition and contextualisation of the performance- lecture}

The performance-lecture, as its name indicates, locates between a performance and a lecture, taking elements from these two forms; thus we could say that it is a hybrid form. Since the 1990 s, the form of the performance-lecture is gaining relevance within a varied range of artistic practices, and more and more visual and performance artists use and explore this heterodox format. The performance-lecture allows infinite variations depending both on the work content and also on its presentation form. However, David Ladnar notes that 'despite the continuing ubiquity of the label "lecture-performance", or possibly because of it, the question of what actually constitutes a lecture-performance is still contested. Or, in other words: even if the label is applied, it is seldom considered what it stands for' $(2013,2)$. Ladnar makes a noteworthy remark on the contexts where the lecture-performance operates, he comments that 'the contexts in which the lecture performance has emerged and in which it participates are manifold, and cannot often be clearly defined as either artistic or academic' (2013,3-4). This point on these different contexts will be tackled later on in this paper as it sheds light on how the research/work How to open my eyes? has been presented and the different forms it has taken.

Attending to the bibliography on the performance-lecture, there seems to be a lack, or at least dearth, of studies (Ladnar, 2). Further, within the scant bibliography in English on this notion we find the terms 'performance-lecture', 'lecture-performance', and also 'performative lecture' and the distinction between them is unclear ${ }^{1}$. This diverse terminology also indicates that what constitutes this form is still open. Indeed, it could be argued that the notion of the performance-lecture hasn't been 'pigeonholed', and this openness, in the sense of lack of definition, might be one of the most important features, and as suggested this might be reason why so many artists operate within this form in recent years.

Although the goal of this paper is neither to define the notion of the performance-lecture, nor to track a genealogy of this complex form, it might be useful to attempt to situate the form of the performance-lecture historically. For some authors, the performance-lecture would participate of the tradition of artists' lectures and the history of performance (Rilke, 6). Here, Robert Morris' 1964 re-enactment of art historian Erwin Panofsky's lecture 'Studies in Iconology' is cited as the first lecture-performance. In addition, other seminal examples of performance-lectures would be the slide-lecture Hotel Palenque from 1969-72 by Robert Smithson and also the talk-pieces developed by the American poet David Antin (Rilke, 6). Also, the performance-lecture might be pondered as 'a continuation of artistic explorations in and through Happenings, body art, and performance since the 1960s (Maaike Bleeker 2013, 183). These seem to be most common lineages of the form of the performance-lecture. However, this paper discusses the relationship between the performance-lecture and the filmessay, a relationship that the development of the research/work How to open my eyes? confirms.

\footnotetext{
${ }^{1}$ Within my investigation, I decided to use the term performance-lecture.
} 
During my investigation I attended several performance-lectures by visual artists and performers such as Rabih Mroué, Hito Steyerl, Asier Mendizabal, Elisa Arteta and Emma Cocker. Some of them are also academics. Their works can be characterised by the productive interplay between the discursive narration (as a theoretical one) and the materials (visual materials or dance/movement). Within this interaction, spectators need to attend both to the voices/words and to the images as both deliver the content of the work.

Among these performance-lectures, I want to highlight Rabih Mroué's The inhabitants of images $^{2}$ as it constituted a significant affective encounter for me. Rabih Mroué is an actor, musician, playwright and visual artist who was born in Beirut in 1967. His work constitutes a radical interrogation of memory, power and the construction of truth and it is always connected to the different images produced by the war in Lebanon. The inhabitants of the images starts with the martyrs' images that circulate in Beirut, both in the streets as posters and in the media, to develop a very personal poetic and political narration that never shows a fixed position.

\section{The case study: How to open my eyes?}

This section will describe the relevant features of the research/work How to open my eyes? to provide an adequate understanding of it. Also, it will explain the different presentation forms and the diverse contexts where this work has been shown, as this is significant to the ongoing argument.

As an overview, in the research/work How to open my eyes? (2012), a narrating voice-over (pre-recorded) talks over while I handle different photographic materials (old photographic papers that have never used, a book that is missing one photograph, black and white photographic film, and Google Earth on an ipad). Within this research/work the voice-over and the handling of the materials are equally important; both expose and also shed light into some of my enquiry's concerns. As it will be explained throughout this paper, the handling of the materials evidences that it is through performativity that one notices the materials properties of photographic images in specific ways. While the voice-over, at the same time, theorises on the functioning and the functions of images.

Regarding the different contexts where this research/work has been shown, How to open my eyes? was performed live as a performance-lecture in two occasions in 2012. The settings in these two instances were very different. Later on, in 2015 I produced a video essay with this research/work.

Recapitulating on the context of production of How to open my eyes?, it was developed for a seminar that took place during the Summer Lodge ${ }^{3}$ in Nottingham Trent University in July

\footnotetext{
${ }^{2}$ Rabih Mroué performed this lecture that he defines as a non-academic lecture in CA2M, Centro De Arte 2 de Mayo in Madrid in 2011 during the Symposium 'XVIII Jornadas de La Imagen de la Comunidad De Madrid. Historias que no se han escrito'. Mroué showed this work for the first time in 2009.

3 'Summer Lodge is an annual event where for ten days each July, the Fine Art studios and workshops of Nottingham Trent University are transformed and play host to a gathering of diverse artists. It is intended as an opportunity to think through making by being able to work for a while without many of the usual constraints and distractions. It is a collective space in which to undertake experiments, pursue new ideas and allow unexpected leaps of imagination. Participants in the Summer Lodge will include current NTU tenured and hourly paid staff, artists working in the city of Nottingham and beyond, and student assistants with the aim of
} 
2012. This seminar uses the format of a Pecha-Kucha ${ }^{4}$ session, each presenter showing twenty images, each for twenty seconds. For my presentation, the format was slightly subverted. I pre-recorded the voice-over, allowing twenty seconds for each part. And the showing of the visual materials was done live in a lecture-theatre making use of a visualiser device ${ }^{5}$, instead of using powerpoint.
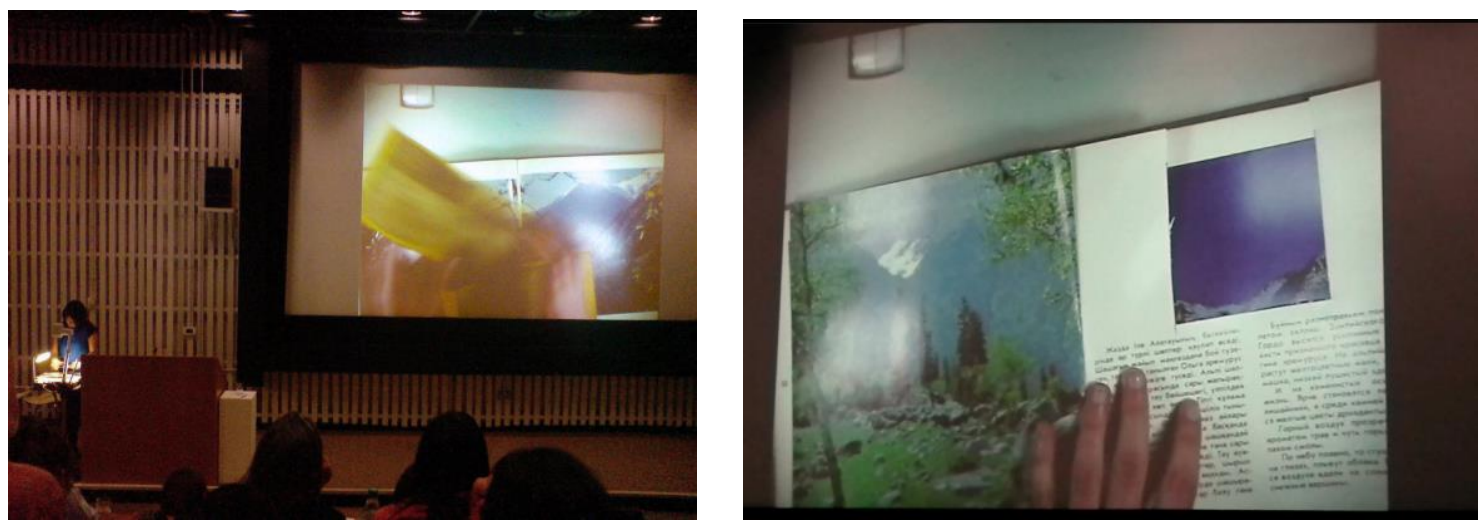

Figure 1. 2. How to open my eyes?, Summer Lodge, Nottingham Trent Univeristy, Nottingham, July 2012.

For the second occasion, How to open my eyes? was presented again as performance-lecture in a different setting and context. This time, in October 2012, it was presented as an artist's practice in the artists' studio Primary ${ }^{6}$ in Nottingham. Here, the location was a small room, instead of a lecture theatre, and the audience was comprised of twelve people. Instead of the visualiser, I employed a camera mounted on a tripod and situated on the table, to show the live-footage of the performing of the photographic materials on the wall that was behind me. Another key difference in this second occasion was the proximity between the audience and I that brought about new issues such as my physical presence and the interplay between the image projected on the wall and the actual artist's body. Therefore, as stated above, these changes evidence that the form of the performance-lecture allows for infinite variations.

Below you can find some documentation from the performance-lecture in Primary alongside the narration/script. This was the form the research/work was presented in the written component of the thesis.

initiating new dialogues and critical exchange through engaging together in a period of sustained studio/workshop practice'. Documentation of previous Summer Lodge is available online at: http://www.summerlodge.org/, last accessed 21/01/2015.

Within my investigation the Summer Lodge has had a crucial role to challenge my practice testing out new things.

${ }^{4}$ http://www.pechakucha.org/, last accessed 14/08/2015.

5 This description of this device states that they 'can be used to display images of books, experiments or any 3dimensional objects, for example items which normally would be passed around a class can instead be seen simultaneously by all students while the teacher describes and explains it'.

http://www.aclasstechnology.com/interactive-classroom-products/ezVision/, last accessed 14/08/2015.

6 'Primary is an artist-led space that exists to support creative research and to develop new ways of engaging audiences. Offering dedicated artists' studios alongside more flexible spaces, both within and outside the building, where artists from around the world can meet and work in the heart of Nottingham. Primary is a place where artists and the public can share, experiment and learn about contemporary visual art through an ambitious programme of events and activities'. More information http://www.weareprimary.org/about/, last accessed 14/08/2015. 

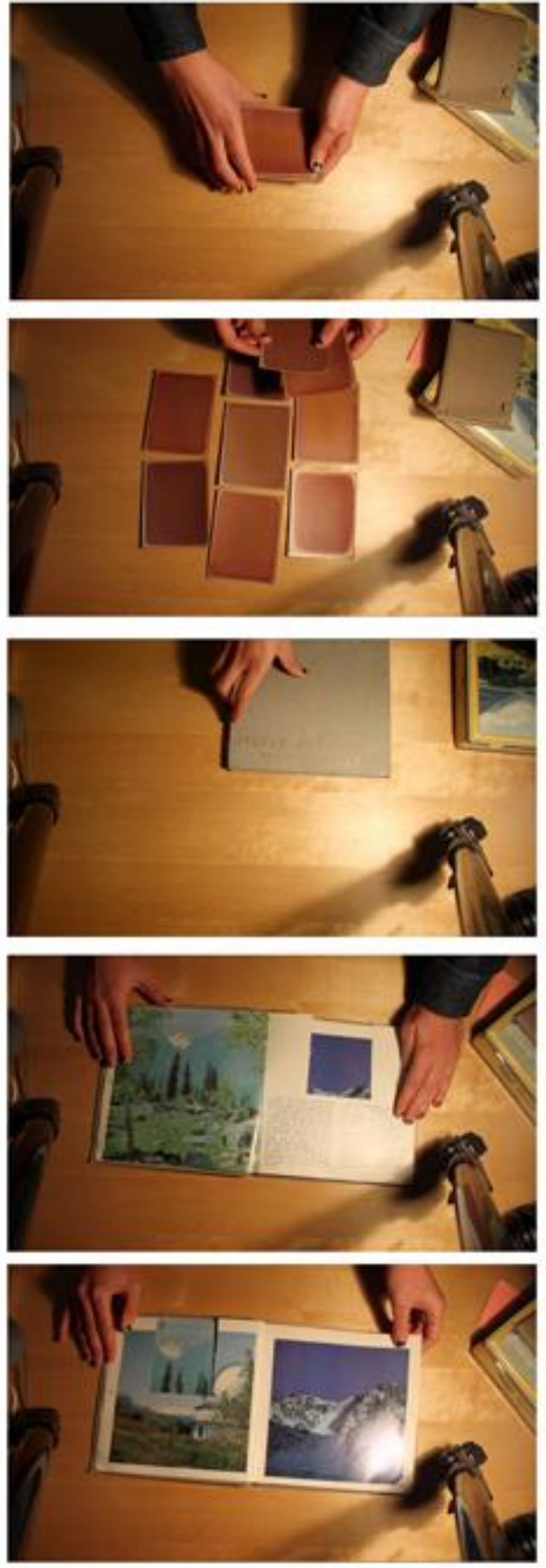

Figure 3. How to open my eyes?, Primary, Nottingham, July 2012.
How to open my eyes?

How to open your eyes?

Let's start with an image.

An image that isn't an image. Although it is an image and many images at the same time.

This image conveys many images and none at the same time.

This collodium self-toning paper was never used, I opened this envelope full of old photographic papers, and they had silver and bronze tones.

Every time these papers are exposed to light they change,

And I wonder if the same could happen to other images that surround us.

So now I question if it is possible to have an inquisition into images, if we can interrogate them, and if images are things or do they belong to an other category?

Joaquim Koester believes that when we are uncertain is when we start seeing, During last year I got lost among images to find answers and now I look for images to get lost in.

I tend to appeal to the images, sometimes I ask them for explanations and many times images are my interlocutors.

As it happens with this book, this book raises a question, does landscape exit only because a frame exists?

And I ask, who did cut this page? What for?

And what if we think on images as territories, as houses, as cities with evacuations and moves... then which are the images' thresholds? 
As a third iteration, the research/work How to open my eyes? took the form of a video essay for the 'research exhibition' that was a key component of my PhD submission. Here is a link to the video essay, and a detail.

https://vimeo.com/123319533

Password: Eyes

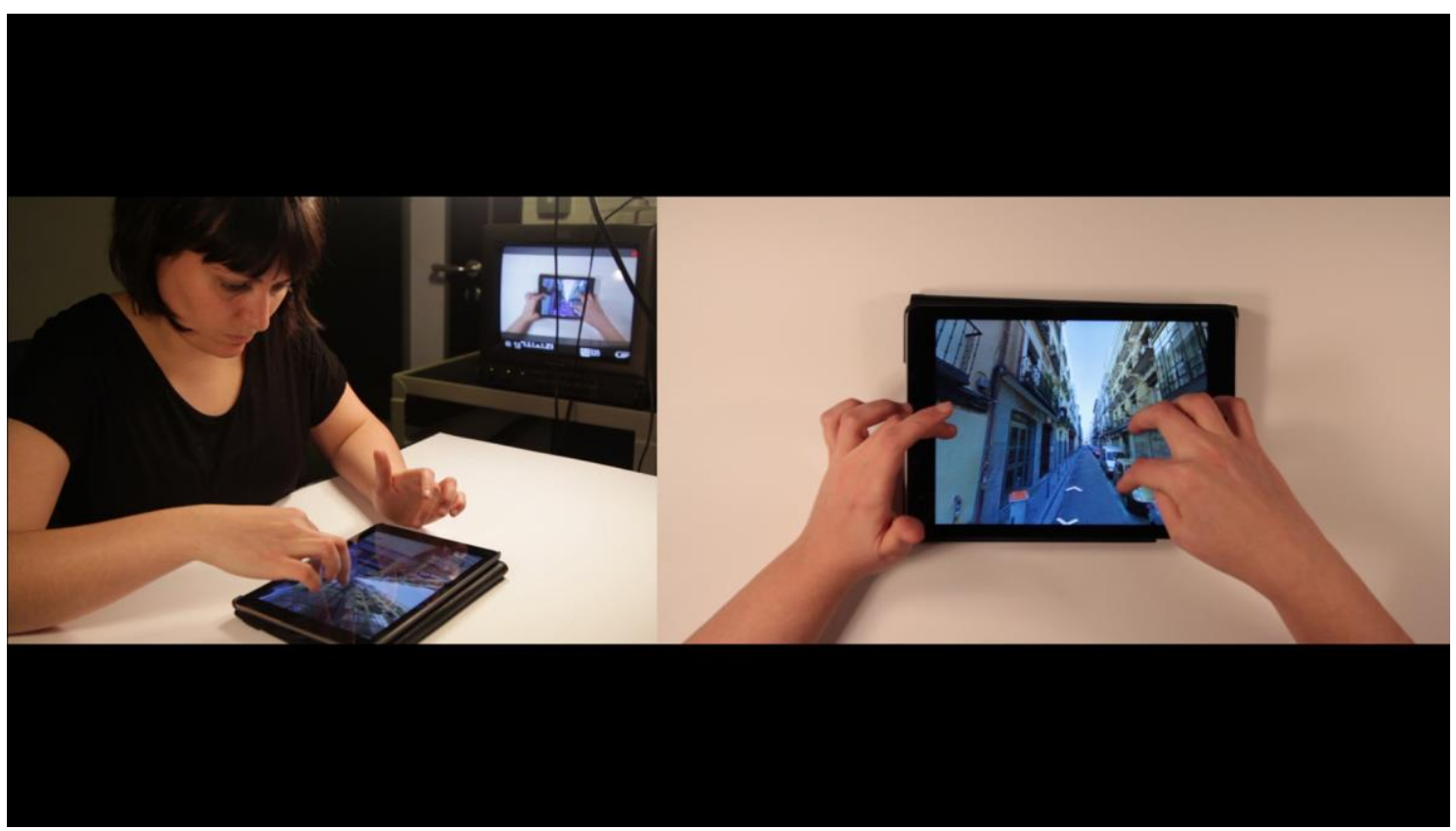

Figure 4. How to open my eyes?, 2015, video, 5:22 min. detail.

The role of the 'research exhibition' was to expose the enquiry and the main findings. The 'research exhibition' was organised in two spaces: one gathered three artworks that articulate some of the main findings of this investigation, while the other gathered together works produced at the beginning of the investigation with research/work that help one to understand additional aspects of the methodology of this investigation. In this case I refer to the interplay between thinking and making as I will expand on later in this paper.

A long time was spent pondering on how to show How to open my eyes? in a more conventional exhibition display, transferring the live-work to a screen but maintaining its significant components. In February 2015, I turned the performance-lecture into a video. The video is organised through a split-screen that shows two points of view: (a) one of the materials in a very clean (almost clinical way) and (b) one that focuses on myself handling the materials, showing the arms and a view of the setting used to capture this footage. Importantly, this split-screen tries to imitate the doubling that spectators experienced when How to open my eyes?, was performed in Primary in a small room. 


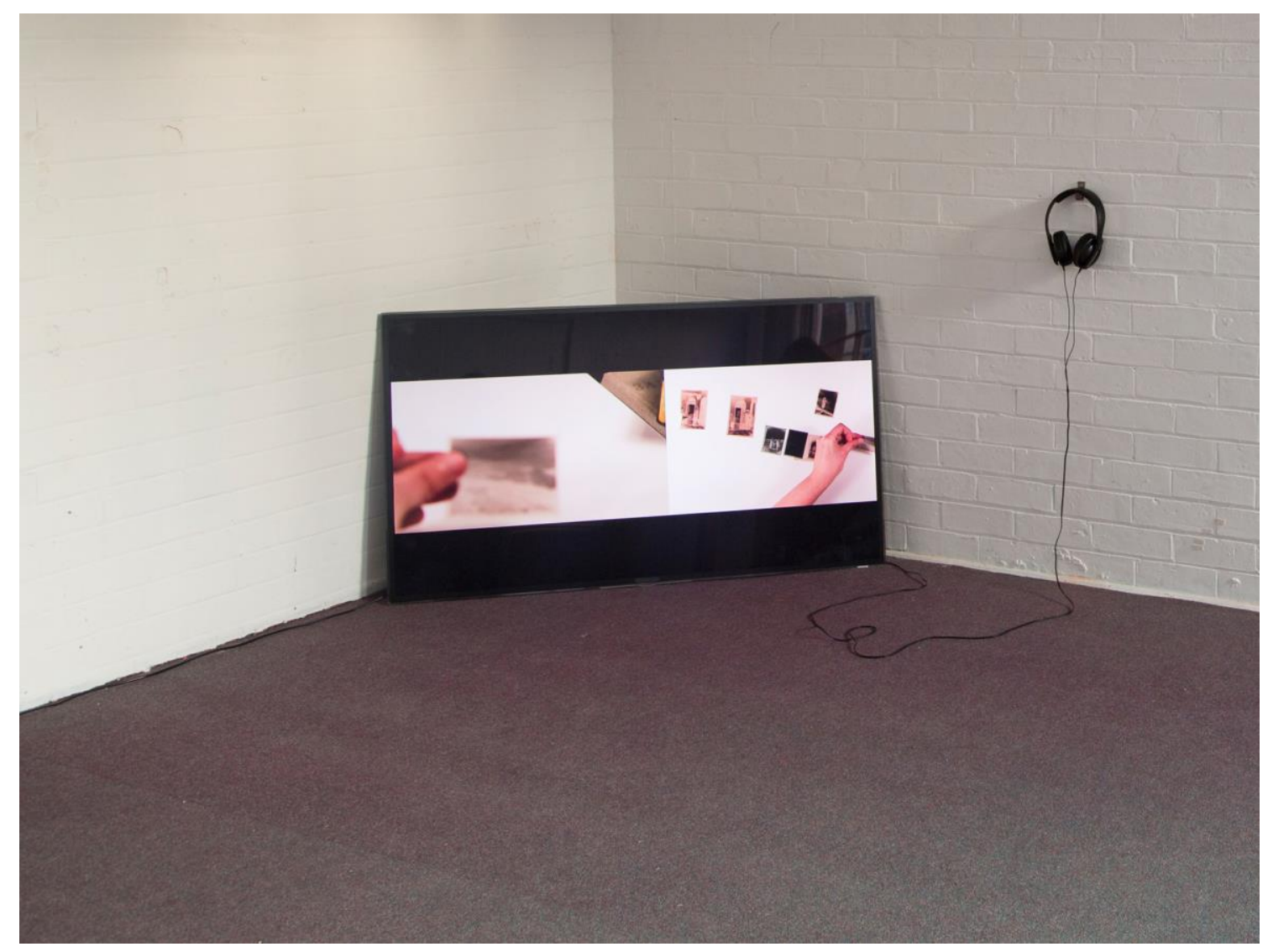

Figure 5. How to open my eyes?, 2015, 'research exhibition', installation view.

The photographic materials employed in How to open my eyes? are apparently banal and everyday, and they are of four types. Firstly, the old photographic papers never used are images that, paradoxically, don't have any image content. They are just the photographic materials. However, every time this performance-lecture has taken place - and also every time the envelope has been opened - they darkened. This way, these materials indicate the photographs' materiality and also how photographs do change with time and usage. This issue of usage is highlighted by the second photographic material, a photographic book in which a photograph is missing. These two photographic materials express the materiality of photographs (their plasticity and physicality). Further, they also point out how materiality carries the physical inscriptions of use and time. The third photographic-material is Google Earth $^{7}$ on an ipad, and in this case the hands indicate the performativity of contemporary digital images. Lastly, the forth photographic-material employed in How to open my eyes? are black and white negatives that show the rural Spanish. These negatives would belong to the category of the snap photo, this way they refer to the amateur uses of photography.

\footnotetext{
${ }^{7}$ Google Earth is software that provides images of most of the world that has been produced by Google. Further, Google Earth could be defined as another consumer and capitalistic photographic product, which entails economic and political power.
} 


\section{'Performing documents', performance and performativity in How to open my eyes?}

This section of this paper will focus on how the notion of performance participates in the research-work How to open my eyes? examining how the notions of performance and performativity operate in the tactic that I have called 'performing documents'. Within my investigation I have analysed the complex and contested notion of performance drawing upon J.L. Austin's and Judith Butler's understandings and also Erika Fischer-Lichte's insights on the aesthetics of performance and its eventfulness within theatrical studies and Elena Del Río's affective-performative concerns influenced by Gilles Deleuze.

In linguistic theory J.L. Austin introduced the concept of the performative in his lecture How to Do Things with Words (first delivered in 1955) attempting to distinguish between 'constative' and 'performative' utterances. For Austin, the first ones function as statements that describe or report while the second ones perform an action; his exemplary utterance is the 'I do' pronounced in a wedding that has the effect of producing a marriage. Consequently, this utterance has a 'performative force' as it produces, as it does, something.

Later on, other philosophers such as Jacques Derrida, Judith Butler and Maurizzio Lazzarato have studied the notion of performativity. For Derrida, a performative act entails a transformative and provocative power. Butler discusses how identity and gender are constructed through performed acts (1999); therefore they are mutable or fluid and within her understandings, the concept of the speech act is itself a form of action (Bruzzi, 52).

In How to open my eyes?, I handle and perform different photographic materials using the tactic I have named 'performing documents' ${ }^{8}$ that emerges from the operation of handling physical photographic-materials, and it has varied depending on the research/works. The term performing is applied to the productive activation that occurs in this 'affective encounter' following the ideas just discussed. And the use of the term documents relates to the understandings of photographs as documents ${ }^{9}$-(a) photographs as evidence, (b) photographs as something to teach us, and (c) photographs as catalysts of events. With regard to the notion

\footnotetext{
${ }^{8}$ Performing documents, or performing the document has been used in different artistic contexts in the last years with a different meaning.

Performing documents was a major collaborative research project, which asked how we are dealing with the remains of Live Art today; it consisted of a series of performance workshops, symposia and a conference among others. Some information about this project can be found here:

http://www.bristol.ac.uk/arts/research/performing-documents/.

In addition, is the article Performing the document: New Political Theatricalities - written by curator and critic Guillaume Désanges - he addresses some artistic practices that make up new documentation when it doesn't exist or is missing- such as Eric Baudelaire's - http://baudelaire.net/extras/biblio/2014_ESSE.pdf

${ }^{9}$ Thoman Keenan and Hito Steyerl have discussed what a document might be, see references. Keenan tracks the etymology of the word document, which goes back to an original meaning of to teach, coming from the Latin docere. This indicates that throughout the centuries the notion of document as a lesson shifted to the current 'evidentiary proof' that is not exactly the same. Besides, some present-day understandings of documents point out that once a document is 'launched, any kind of document, can go on to create a new reality by means of the constituency that shared, spread, sustained, and built it', as Steyerl points out complicating the question of what documents might be. This way Steyerl highlights the important shift from understanding documents as evidence to the 'document as trigger and catalyst of events', which occurred over the last few decades.
} 
of performance and performativity, this last understanding of 'photographs as catalysts of events' is particularly pertinent ${ }^{10}$.

Photographs are catalysts of events and performance is considered an event, in theatrical studies the notion of performance, which has also been key, and it 'lies shift from theatre as a work of art to theatre as an event' as Erika Fischer-Lichte comments (2008, 36). Importantly, for this discussion on the performance-lecture, in Fischer-Lichte's account of performance 'presence' and 'representation' are blurred, and this is an important characteristic of How to open my eyes?.

For Elena del Río, based on Deleuze's understandings of the body as an assemblage of forces or affects that interact with other forces or affects restoring to the body the dimension of intensity lost in the representational paradigm, performance is an 'expression-event of unassimilable affect (unassimilable to language, binary structures, and ideological functions)' $(2008,4)$. She also highlights the importance of the body as a producer or receptor of the affective event. Therefore, following these accounts, performance is not just a kind of artistic production-intervention (although it is commonly used as that); also it could be defined as an experience becoming an expression-event. Thus she argues for 'the mutual imbrication of affect and performance'(2004, 10).

Furthermore, recently Toni Negri has discussed the role that performance might have in activating life and leading us to resistance. He ponders on how the performative might be able to, as it crosses with art and life, activate reality and how it leads us to resistance, although it might be an event and leading to something ephemeral or negative (Negri 2014, 41). For Negri:

'the performative becomes a creative act. It opens and does not close existence; unceasingly [...] Performance helps us to go beyond anguish because its experience is bodily and its body powerful. Performance leads us back to the subject that produces reality [...] Performativity builds things, horizons, issues, themes, projects.' (44)

Summing up, these aforementioned key understandings of performance as an expressionevent have illuminated the operations of some of the main features of the critical method in How to open my eyes?. Also this research/work has created new understandings on how performance and the body might produce new knowledge on images. Therefore, the research/work How to open my eyes? indicates that performance might be an excellent instrument to apply to existing photographs in order 'to put them into motion-action'. Finally, keeping in mind that performance affects both the performer and the spectator, I argue that the tactic 'performing documents' within the research/work How to open my eyes? activates photographs in order to make the spectator think-feel-know.

\section{The lecturing in How to open my eyes?}

This part of this paper will analyse the functioning of the lecturing/voice-over in the research/work How to open my eyes? addressing how it theorises on images and produces knowledge in an experimental way that challenges some of the restrictions of academic research. This section will tackle the lecturing in the performance-lecture illuminating how

\footnotetext{
${ }^{10}$ Indeed the voice-over in How to Open my Eyes? says: 'After having collected pictures for a while I have been thinking in the potential of performing documents because all photographs at the end are documents'.
} 
the lecturing/voice over is speculative and essayistic. This examination, importantly, will also situate the performance-lecture in the terrain of the film essay.

As has been noted, the research-work is composed by a performative part in which I perform different photographic materials-documents. The other key component is the discursive narration that encompasses the thinking, writing, telling, lecturing and the voice-over. Importantly, the discursive does several things at the same time: it theorises on images creating new knowledge and it also enables an artistic practice that also constitutes artistic research in itself.

Within my use and understanding of the performance-lecture, it is noteworthy to ponder on the alignment between the critical method of the performance-lecture with the film-essay, or the essay film, as noted by Frank (8). Thus situating the performance-lecture within the genealogy of essayistic practices, primarily the film-essay and the video-essay, enables a better comprehension of the development and the functioning of research/work How to open my eyes?. Hans Richter coined the term film essay in 1940 as 'capable of visualizing theoretical ideas' (Steyerl 2010) and it gained prominence in 1960s and 1970s. Again, defining the film-essay is a difficult endeavour, however these are some of its main features: proposition of a personal and non-systematic discourse, usage of personal style, an edition that privileges words and/or the filmic presence of the author (García 2006, 75). García also explains that the essay form presents and exposes ideas in a personalised and non-systematic way, being an intellectual inquiry that shows speculation during its production (75).

In Theodor Adorno's text, The Essay as Form, he comments on 'the resistant characteristics of the essay as subversive method of thought' capable of 'reshuffling of the realms of the aesthetic and epistemological' (Steyerl 2010). For Adorno: 'The essay, however, does not permit its domain to be prescribed. Instead of achieving something scientifically, or creating something artistically, the effort of the essay reflects a childlike freedom that catches fire, without scruple, on what others have already done. For Rike Frank, the film essay would be another 'an analytical form that turns attention to the way we experience information' [...] This way the film-essay is an important antecedent 'of a politicised mode of undermining authority'(8).

Hito Steyerl has noted that the one important method of artistic inquiry is the essayistic. For her the essayistic is based on several 'related sets of conflict and crisis' (2010). Then, concerning the relationship between the performance-lecture and research, it could be argued that the method of the performance-lecture might contribute 'renegotiate the relations between art on the one hand and science or scholarship on the other' (Ladnar 2013, 3-4) by interrogating what constitutes knowing and knowledge.

Returning to the case study, the research-work How to open my eyes? performs the enquiry reflecting on working processes. Further, more importantly, it 'feature(s) a kind of not knowing... which does not represent a lack, which is not obscure, ignorant, or non-scientific but which produces an event beyond knowledge' (PIrkko Husemann 2014).

Therefore, within artistic research, the critical method of the performance-lecture enables an experimental examination and re-negotiates the production and the distribution of knowledge. In connection to this production of knowledge, Ladnar argues that 'the lecture performance can be read both as an example and as a critique of the role of knowledge production and presentation in today's society' (28). 
In addition, in How to Open my Eyes? 'the research does not simply exist independently to its presentation $^{11}$ (Peters 2011), thus the significance of the interplay between what it is being said and how it is being said. Therefore in How to Open my Eyes? the performance informs the presentation form and also the lecturing (the narrating voice-over) informs the form shaping and re-shaping new understandings. In How to Open my Eyes? artistic theory fusions with artistic practice that demonstrates the relation of 'art and research (Ladnar, 40). Thus, as How to open my eyes? demonstrates, the heterodox and idiosyncratic artistic tactic of the performance-lecture can become crucial for artistic enquiries. Through this tactic of the performance-lecture I resolve and I arrive at the reflections and conceptualizations. This through is key as the form of the performance-lecture allowed me 'to think' with images.

Hence, in connection to the issue of the discursive, in the performance-lecture it is a different voice, a different type of writing. This writing is speculative and makes a proposition and it also produces theory. Thus, the heterodox and idiosyncratic artistic tactic of the performancelecture is part of this enquiry's methodology. Through this tactic I resolve and I arrive at the reflections and conceptualizations. This through is key as the format of the performancelecture allowed me 'to think' and to use images-materials. Thinking with images, this is part of my methodology, using images to think with.

Through examining my research/work How to Open my Eyes?, this paper has contributed to the study of the functions of the performance-lecture as critical method within artistic research. This examination proposes that the form of the performance-lecture enables an ongoing interplay between theory and practice, between the thinking and the making and between the making and reflection. Further, the performance-lecture challenges these established categories and helps to re-think the production of knowledge within academic contexts. Thus this paper advocates that the performance-lecture (and the video essay) is a practice that produces theory.

\section{References}

Adorno, T.W. (1984) 'The Essay as Form', New German Critique, no. 32, pp. 151171

Austin, J. L. (1975) How to do Things with Words, Oxford: Oxford University Press

Bleeker, M. (2012) 'Performing the Image: Rabih Mroué's Lecture-Performances' in Costinas, C., M. Hlavajova, and J. Winder (eds) Rabih Mroue, a BAK Critical Reader in artists' practice, Utrecht: BAK, pp. 178-199

Butler, J. (1999) Gender Trouble, New York and London: Routledge

Cerezo, B. (2015) 'What is it "to move" a photograph? Artistic tactics for destabilising and transforming images', Doctoral thesis, Nottingham Trent University. (2012) Rabih Mroue, a BAK Critical Reader in artists' practice, Utrecht: BAK

De Certeau, M. (1984) The Practice of Everyday Life, Berkeley: University of California Press

\footnotetext{
${ }^{11}$ quoted from Peters, 2011. Der Vortrag als Performance. Bielefeld: Transcript. p.211. in Ladnar, p.40.
} 
del Río, E. (2008) Deleuze and the Cinemas of Performance: Powers of Affection, Edinburgh: Edinburgh University Press

Fischer-Lichte, E. (2008) The Transformative Power of Performance: A New Aesthetics, New York and London: Routledge

Frank, R., 'When Form Starts Talking: On Lecture-Performances', Afterall: A Journal of Art, Context, and Enquiry, vol. 33/no. 1, 2013, pp. 4-15

García, A. N. (2006) 'La imagen que piensa. Hacia una definición del ensayo audiovisual', Comunicación y Sociedad, 19, 75-105

Husemann, P., 'The Absent Presence of Artistic Working Processes. The Lecture as Format of Performance', performance-lecture, Frankfurt, 5/8/2004 (English version, Update March 2005) Available at: http://www.unfriendlytakeover.de/downloads/f14 husemann engl.pdf Last accessed 5 October 2014

Keenan, T., and Steyerl H. (2014) 'What is a Document? an Exchange between Thomas Keenan and Hito Steyerl', Aperture, 214, 58-64

Ladnar, D. (2013) 'The lecture performance: contexts of lecturing and performing', Doctoral thesis, Aberystwyth University

Negri, A, (2014) 'Construyendo lo común. Performance como praxis' in Pontbriand C. (ed), Per/Form, How to Do Things with(out) Words, Stenberg Press, CA2M, pp. 34-45

Steyerl, H., (2010), 'Aesthetics of Resistance? Artistic Research as Discipline and Conflict', Mahkuzine, Journal of Artistic Research, 8. http://issuu.com/hkuonline/docs/mahkuzine08 web Last accessed 5 August 2015

Belén Cerezo is an artist-photographer, researcher and educator. Within her practice and research, photography operates as the guiding notion. Through a focus on the materiality of images, she explores photography through performance attempting to renovate the discourse on images. Belén Cerezo has just completed the practice-led $\mathrm{PhD}$ at Nottingham Trent University "What is it to move a photograph? Artistic practices for destabilising and transforming images". Cerezo is an associate lecturer in Photography. She is also interested in art education and she co-coordinated the Education Department for Manifesta 8, Murcia, Spain, 2010. Cerezo published the photo-book Somewhere Better, Nowhere Better in 2009. She had a solo exhibition titled Plastic People at CAB in Burgos, Spain, in 2008.

Email: cerezobelen@gmail.com 